\title{
Наше контрактное производство растет, но мы ищем идеи, чтобы усилить этот рост
}

\author{
Рассказывает председатель совета директоров группь компаний \\ «Макро Групп»Д.А. Велеславов
}

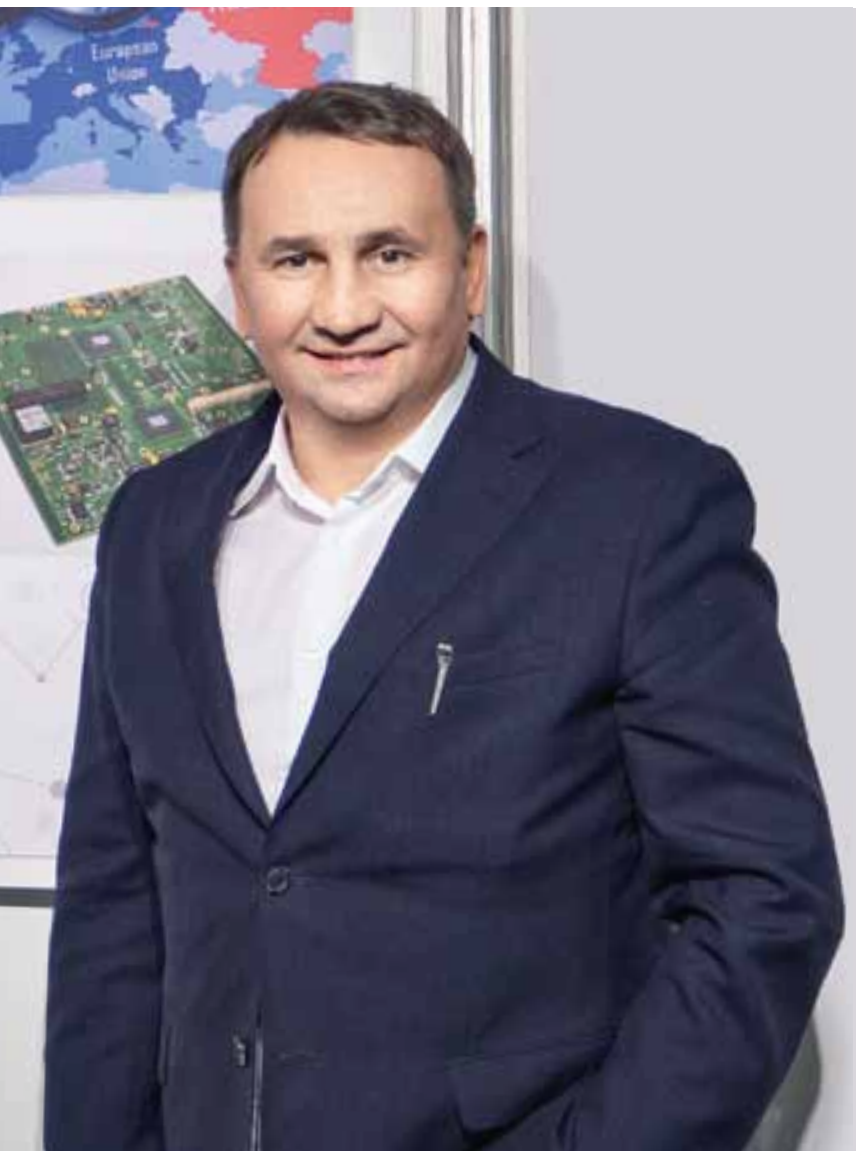

В ноябре прошлого года ООО "Макро ЕМС", входящее в группу компаний "Макро Групп", приняло участие в выставке productronica 2019 в Мюнхене. Компания с 2012 года оказывает услуги контрактного производства электронных сборок на российском рынке.

В чем заключалась цель ее участия в европейской выставке, как контрактного производителя из России, стало первым вопросом, заданным нами на стенде компании Дмитрию Александровичу Велеславову, председателю совета директоров группы компаний "Макро Групп", который также рассказал нам о планах компании по развитию производства, о текущем состоянии отечественного рынка контрактной сборки и дистрибуции электронных компонентов (а "Макро Групп" обладает 25-летним опытом поставок ЭКБ) и поделился своим мнением о том, как российский контрактный производитель может конкурировать с производствами из других стран.

Дмитрий Александрович, ваша компания впервые принимает участие в выставке productronica со своим стендом. С какой целью вы приехали сюда?

Одной из крупных стратегических задач, которые мы поставили перед собой в 2018 году, является разработка экспортной стратегии. Мы изучали статистику экспорта и обратили внимание, что по всем отраслям в 2018 году со своими продуктами на зарубежные рынки вышло около 6 тыс. российских компаний. И мы задались вопросом: «Почему бы и нам не попробовать?»

Но разработать экспортную стратегию невозможно, не имея представления о том, что востребовано на целевых рынках, что ждут от нас потенциальные заказчики, как правильно позиционировать себя.

Именно сбор информации и является основной целью нашего участия в этой выставке. Мы не ждем от нее немедленных результатов, прорывов. Мыхотим понять, есть ли в принципе интерес к российской контрактной сборке в Европе и, если да, какие существуют требования у зарубежных клиентов, чтобы оценить, что нам нужно сделать, чтобы их удовлетворить, и как быстро это может у нас получиться.

У нас уже появились определенные контакты, которые показывают нам, в каком направлении стоит двигаться. Например, мы отметили, что есть западные компании, работающие на рынке автомобильной электроники, которые готовы рассматривать контрактную сборку своих изделий в России. Но для того чтобы мы могли оказывать им эти услуги, мы должны получить ряд сертификатов. Это информация, ради которой уже стоило сюда приехать. Теперь можно выстраивать планы последующих действий, улучшать процессы, готовиться к необходимой сертификации. Без такой информации предпринимать дальнейшие шаги было бы очень сложно. 
Вероятно, цели экспортной стратегии выходят за рамки желания попробовать. Каких результатов вы ждете для компании от выхода на зарубежные рынки?

Прежде всего, мы видим в экспорте диверсификацию - не по продуктам, а по географии заказчиков, что очень важно с точки зрения управления рисками. Это сделает нашу компанию более устойчивой.

Кроме того, мы заинтересованы в развитии наших технологий и компетенций, в том, чтобы построить производство действительно мирового уровня, и надеемся чему-то научиться у зарубежных заказчиков. Те требования, которые нам предъявляют российские клиенты, мы хорошо знаем и отвечаем им, неоднократно проходили различные аудиты, подтверждали соответствие. А зарубежные аудиты мы не проходили ни разу. И в качестве одной из целей работы с зарубежными заказчиками мы видим то, что они по крайней мере покажут нам стандарты, к которым мы должны стремиться. Собственно, упомянутый пример с автомобильными сертификатами - шаг в этом направлении.

Означает ли то, что вы поставили на первое место географическую диверсификацию, отсутствие потенциала роста на российском рынке?

Нет. Мне кажется, что российский рынок контрактного производства чувствует себя неплохо. Мы позитивно оцениваем его потенциал.

Если мы рассмотрим дистрибуцию электронных компонентов, то в этой области рынок почти не растет. В основном здесь происходит перераспределение между игроками: часть оттягивают на себя глобальные дистрибьюторы, такие как Avnet, Arrow Electronics и т. п.; часть проектов переходит от одного локального дистрибьютора к другому. На этом рынке всё сложнее конкуренция, всё серьезнее ценовая борьба. Дистрибуция электронных компонентов никогда не была простым бизнесом, но сейчас это стало особенно ощутимо.

Рынок контрактного производства выглядит совершенно по-другому. На нем основные игроки заняли свои ниши, в которых вполне хорошо себя чувствуют. Борьбы за действующие проекты, как это происходит в дистрибуции, здесь нет. Я думаю, что ужесточение конкуренции случится и в этой сфере, но пока есть временной запас для того, чтобы спокойно наращивать производственные мощности и развивать технологии.

При этом сам рынок растет, и растет, скажем так, органически. Появляется достаточно много компаний с очень хорошими идеями, которые перерастают в разработки, занимающие определенные ниши, в том числе в задачах импортозамещения. Не все такие компании хотят организовывать производство у себя. Многим из них интересно найти партнера, который будет производить их продукцию, лучше всего - под ключ, чтобы не брать на себя закупку компонентов, плат, сертификацию производства.
Таких компаний становится больше. Пусть это пока небольшие компании, малый и средний бизнес, но нам с ними интересно работать, потому что они видят долгосрочные тренды, заходят в эти тренды со своими идеями, и в то же время они гибкие, адаптивные к рынку, они стремятся к лидерству в своих нишах. Для таких сфер, как телекоммуникации, нефтегазовая промышленность, промышленная автоматика, российским разработчикам удается создавать решения, достаточно конкурентоспособные по цене и ничуть не уступающие западным аналогам по своим характеристикам. Эти компании вполне успешно замещают импортное оборудование, благодаря чему испытывают рост и тем самым позволяют расти и нам.

Мы постоянно обновляем парк оборудования, набираем новых сотрудников. Сейчас нам уже не хватает площадей будем строить новый производственный комплекс, который, надеюсь, будет готов к концу 2020 года. К уже имеющимся 2,5 тыс. м² производственных площадей этот комплекс добавит нам еще 4 тыс.

По-моему, это лучшая иллюстрация к ответу на вопрос о перспективности российского рынка контрактного производства.

В то же время наш рост по направлению контрактного производства, который сейчас составляет порядка 10-30\% в год, можно было бы усилить за счет работы с зарубежными заказчиками. Одна из идей для такого роста - локализация производства оборудования иностранных компаний. В России специфика рынка такова, что контрактному производителю приходится работать по ситуации, долгосрочных контрактов практически не бывает. А с зарубежным заказчиком возможна договоренность на несколько лет. Поэтому локализация, помимо прироста объемов, может придать стабильности, и одна из задач, которую мы перед собой ставим, найти хотя бы одного-двух таких заказчиков.

То есть вы рассчитываете найти зарубежного партнера, продукцию которого вы бы производили в России для локального рынка?

Мы смотрим в обе стороны: и локализации, когда продукция реализуется на внутреннем рынке, и экспортной деятельности, когда продукция производится у нас и поставляется за рубеж.

Во втором случае вашим ближайшим конкурентом, вероятно, будет Восточная Европа. Как вы оцениваете перспективы ценовой конкуренции с производствами из этих стран?

Мы надеемся, что наши услуги будут дешевле, чем в Восточной Европе, за счет как оптимизации процессов, так и меньшей стоимости рабочего часа. Более того, есть основания считать, что мы можем конкурировать по цене и с Китаем, главным образом потому что там за последнее время достаточно сильно выросли зарплаты. 
Уже есть примеры российских компаний, исторически размещавших свои заказы в странах Восточной и Юго-Восточной Азии, которые теперь переносят производство в Россию.

Вопросы, связанные с таможней, вы предполагаете взять на себя?

Да, и мы не боимся этого. Более того, это наше конкурентное преимущество. Ведь одна из причин, почему в России не закрепились глобальные контрактные производители, как раз в том, что они не смогли в полной мере приспособиться к специфике российской таможни, адаптировать свои процедуры. А у нас есть длительный, четвертьвековой опыт в этом вопросе. Мы очень хорошо знаем законодательство, отслеживаем его изменения. В нашей группе компаний есть отличные специалисты, которые работают с таможней многие годы.

Вы упомянули, что постоянно обновляете парк оборудования. Это только вопрос производительности или на старом оборудовании уже сложно обеспечить выполнение технологических требований новых проектов?

Скажем так: оборудование пяти-десятилетней давности с рядом проектов, с которыми мы сейчас работаем, в принципе не способно справиться. Изделия становятся всё более миниатюрными. Сейчас наши линии ставят компоненты, которые с точки зрения человека выглядят, как пыль.

Кроме того, мы, как я уже говорил, стремимся к тому, чтобы наше производство соответствовало мировому уровню. Для того чтобы сегодня быть конкурентоспособным, необходимо внедрять элементы "умного производства», "Индустрии 4.0", оборудование должно общаться между собой.

Это данность: все игроки, которые смотрят в будущее и понимают, куда движется отрасль, просто обязаны закладывать в свои планы модернизацию производственных мощностей.

Помимо поверхностного монтажа, какие операции сейчас выполняются на вашем производстве и есть ли планы по расширению их спектра?

Прежде всего, мы осуществляем не только поверхностный, но и штыревой монтаж. На производстве есть линия селективной пайки. Также мы выполняем монтаж запрессовкой. Кроме того, у нас организованы отдельные участки отмывки и влагозащиты.

Сейчас мы смотрим в сторону изготовления корпусных деталей и конечной сборки в корпус, потому что у наших заказчиков есть потребность в том, чтобы контрактный производитель на выходе отдавал им законченное изделие.

В проекте нового производственного комплекса у нас предусмотрены площади под термопластавтоматы. Мы задумываемся и об аддитивных технологиях, о 3D-печати металлических изделий - это, возможно, более далекая перспектива.
И, как я уже сказал, мы идем по пути реализации "умного производства». В этом направлении у нас большие планы, направленные на то, чтобы создать фабрику, способную производить электронные устройства с нуля и до конечной сборки.

В общем цикле изготовления электронных изделий есть немаловажный компонент, который обычно стоит особняком, - производство печатных плат. Где сейчас вы заказываете платы и есть ли планы включить этот процесс в возможности вашего производства?

На данный момент мы продолжаем пользоваться услугами наших восточных партнеров. Хотя в России печатные платы изготавливаются и таких производств немало, азиатские производители, по нашему опыту, более гибкие и оперативные. И нельзя не признать, что по технологическому уровню они пока превосходят российские производства.

В наших планах изготовления печатных плат нет: в этой области достаточно много специфики, в том числе в отношении экологии и охраны труда. Но я думаю, что создать в России производство плат современного уровня - не такая сложная задача. Уж точно более простая, чем построить микроэлектронную фабрику. При желании это вполне можно сделать

В заключение хотелось бы узнать, получала ли ваша компания какую-либо помощь в участии в этой выставке от государственных организаций, содействующих экспорту?

Нет, мы принимаем участие в productronica 2019 самостоятельно.

Я знаю, что такая поддержка оказывается. Одна из компаний, входящих в мой портфель, - ООО «Кибертех», которая занимается учебной робототехникой, производит конструкторы для детей, чтобы они могли осваивать данную область. У этой компании есть опыт участия в зарубежной выставке при поддержке РЭЦ.

Здесь можно было стать участником коллективного стенда, организованного центром «Моспром». Но мы решили поступить иначе, организовать свой собственный стенд. Мы посчитали, что таким образом можно лучше обратить внимание на себя, нежели находясь на одном стенде с несколькими другими контрактными производителями из россии.

Конечно, в следующий раз, когда мы решим принять участие в этой или подобной выставке, мы будем смотреть на имеющиеся предложения по поддержке и будем задавать конкретные вопросы, исходя из наших планов и представлений, как мы хотим себя позиционировать на мероприятии.

Спасибо за интересный рассказ.

С Д. А. Велеславовым беседовап Ю. С. Ковалевский 


\section{Система-на-кристалле E XILINX ZYNQ $^{\circledast}$ UltraScale+ $^{\mathrm{TM}}$ MPSoC}

\section{Мощь ARM, помноженная на гибкость ПлИС!}

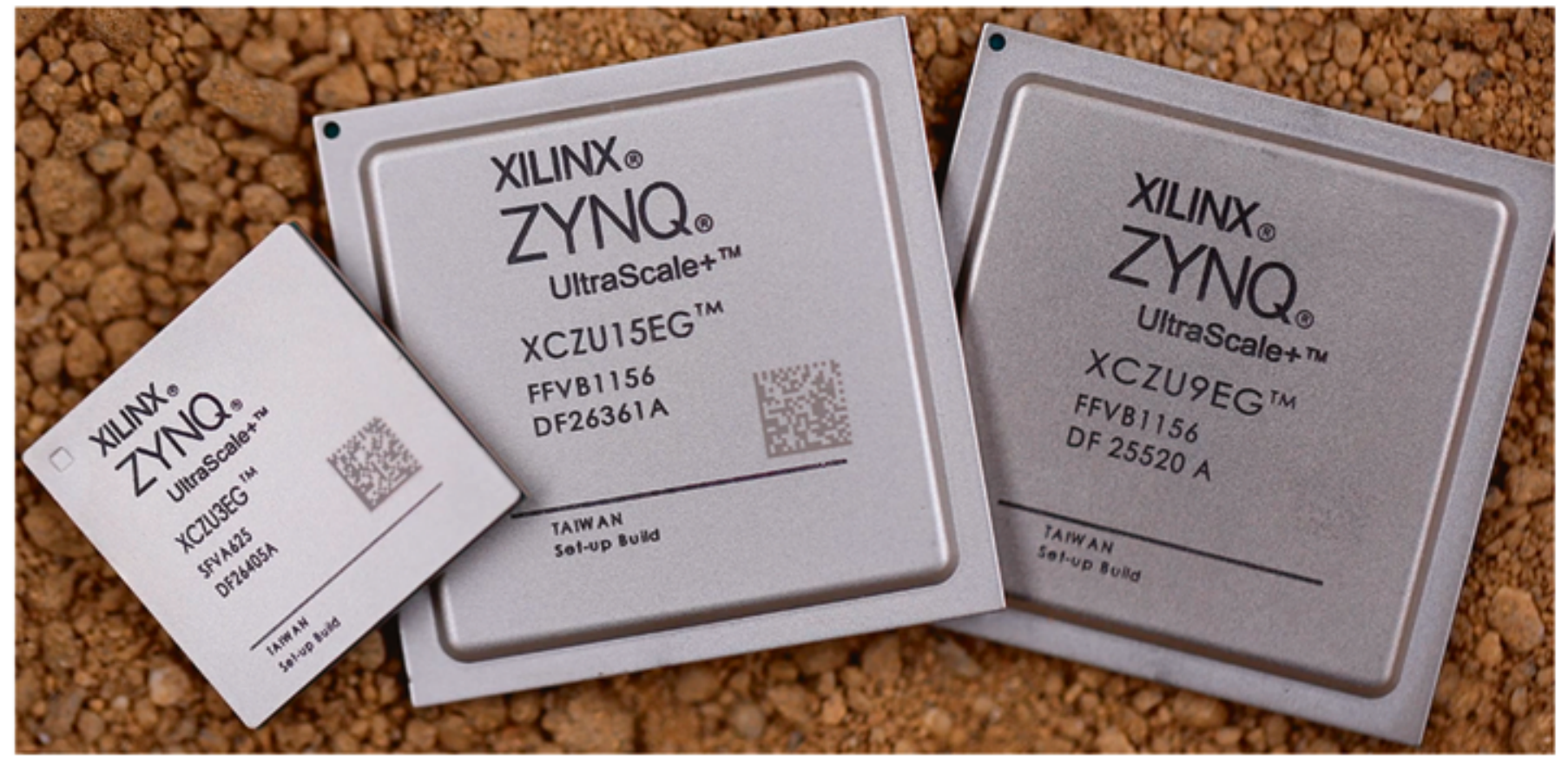

- Забудьте про Verilog/VHDL! Напишите вашу систему на C/C++, отладьте под LINUX и оптимизируйте с помощью программируемой логики. Никогда построение мощных и сложных систем не было столь простым.

- Занимаетесь видеообработкой? Ваш выбор - ZYNQ UltraScale+ EV с 4-ядерным ARM Cortex A53 64 бит, двухъядерным ARM Cortex R5 32 бит и встроенным высокопроизводительным кодеком Н.264/Н.265.

- Создаёте телекоммуникационное оборудование? C ZYNQ UltraScale+ EG это просто. Используйте встроенные IP ядра 100G Ethernet и 150G Interlaken для достижения непревзойденной производительности.

- Создаёте систему управления? Реализуйте все, что вам нужно, на бюджетном чипе ZYNQ UltraScale+ CG.

- Нужно «умное» решение? Создайте собственную свёрточную нейросеть на базе СнK ZYNQ UltraScale+.

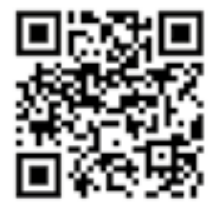

Хотите получить отладку?

Пришлите запрос по адресу fpga@macrogroup.ru

M MAKPO

www.macrogroup.ru fpga@macrogroup.ru

«Макро Групп» - официальный поставщик Xilinx в России Санкт-Петербург (812) 3706070 Москва Екатеринбург Чебоксары

(495) 9880272 (343) 3859510 (8352) 237955
Новосибирск Ростов-на-Дону Минск
(383) 2333487 (863) 2270393 +375 (29) 7718515 